\title{
Genome-wide temporal-spatial gene expression profiling of drought responsiveness in rice
}

\author{
Di Wang ${ }^{1,2 \dagger}$, Yajiao Pan ${ }^{1 \dagger}$, Xiuqin Zhao ${ }^{1}$, Linghua Zhu ${ }^{1}$, Binying Fu ${ }^{1 *}$, Zhikang $\mathrm{Li}^{1,3^{*}}$
}

\begin{abstract}
Background: Rice is highly sensitive to drought, and the effect of drought may vary with the different genotypes and development stages. Genome-wide gene expression profiling was used as the initial point to dissect molecular genetic mechanism of this complex trait and provide valuable information for the improvement of drought tolerance in rice. Affymetrix rice genome array containing 48,564 japonica and 1,260 indica sequences was used to analyze the gene expression pattern of rice exposed to drought stress. The transcriptome from leaf, root, and young panicle at three developmental stages was comparatively analyzed combined with bioinformatics exploring drought stress related cis-elements.

Results: There were 5,284 genes detected to be differentially expressed under drought stress. Most of these genes were tissue- or stage-specific regulated by drought. The tissue-specific down-regulated genes showed distinct function categories as photosynthesis-related genes prevalent in leaf, and the genes involved in cell membrane biogenesis and cell wall modification over-presented in root and young panicle. In a drought environment, several genes, such as GA2OX, SAP15, and Chitinase III, were regulated in a reciprocal way in two tissues at the same development stage. A total of 261 transcription factor genes were detected to be differentially regulated by drought stress. Most of them were also regulated in a tissue- or stage-specific manner. A cis-element containing special CGCG box was identified to over-present in the upstream of 55 common induced genes, and it may be very important for rice plants responding to drought environment.

Conclusions: Genome-wide gene expression profiling revealed that most of the drought differentially expressed genes (DEGs) were under temporal and spatial regulation, suggesting a crosstalk between various development cues and environmental stimuli. The identification of the differentially regulated DEGs, including TF genes and unique candidate cis-element for drought responsiveness, is a very useful resource for the functional dissection of the molecular mechanism in rice responding to environment stress.
\end{abstract}

\section{Background}

Rice is sensitive to drought stress because it is acclimated to either rain-fed or fully irrigated fields. The effect of drought on rice plants considerably varies with genotypes, different developmental stages, and degree and duration of drought stress. Relatively, rice plants are less affected by water deficit at the seedling stage, although drought stress at the vegetative stage does result in reduced height, fewer tillers, and smaller leaf

\footnotetext{
*Correspondence: fuby@caas.net.cn; lizhk@caas.net.cn

+ Contributed equally

${ }^{1}$ Institute of Crop Sciences/National Key Facility for Crop Gene Resources and Genetic Improvement, Chinese Academy of Agricultural Sciences, Beijing 100081, China

Full list of author information is available at the end of the article
}

area. However, rice is highly sensitive to water deficit at the panicle initiation and booting stages [1,2].

Drought tolerance (DT) is a complex trait both genetically and physiologically. Developing DT varieties by breeding is the major strategy for reducing rice yield losses caused by drought. However, to date, few successes have been achieved in this effort because plant DT is a typical quantitative trait influenced by many different genes [3]. Genome-wide genetic analysis of DT has identified many genomic regions associated with drought tolerance or responsiveness [4]. Some secondary traits, such as root architecture and osmotic adjustment, have been identified to be related to drought response [5-7]. Few large and discrete DT quantitative trait loci (QTLs) have been identified and applied to marker-
C Biomed Central

(c) 2011 Wang et al; licensee BioMed Central Ltd. This is an Open Access article distributed under the terms of the Creative Commons Attribution License (http://creativecommons.org/licenses/by/2.0), which permits unrestricted use, distribution, and reproduction in any medium, provided the original work is properly cited. 
assisted selection of DT in rice. However, DT QTL mapping results can be most usefully applied to the identification of promising chromosome regions for the confirmation of functional candidate genes of drought tolerance.

Drought stress causes a wide range of physiological and biochemical responses in plants. These responses include reduced stomatal conductance and photosynthesis, and accumulation of osmolytes and proteins in cells [8]. A number of genes have been identified to be involved in drought response and tolerance, and their functions were confirmed by gene transfer, resulting in plant stress tolerance [9].

With the development of molecular technology and advancement in nanotechnology, DNA microarrays have been devised as a standard strategy for the global analysis of plant gene expression. Microarrays can simultaneously detect thousands of targets in a high throughput manner, and thus their use has enormously expanded to cover all kingdoms of living organisms. The availability of complete genome sequences and of huge EST collections allows the development of different microarray platforms in rice. Several biological processes and important traits of rice have been analyzed using cDNA microarray or whole genome array including salt-responsive genes by cDNA microarray analysis [10], genetic programs involved in pollination/fertilization and stress responses [11], spatial and temporal gene profiling of panicle development [12], comparative analysis of two rice genotypes under salt stress $[13,14]$, drought and high salinity stress responsiveness gene profiling of different organs [15], and grain filing-related genes under high temperature [16]. DNA microarrays provide a high-throughput platform to screen thousands of genes simultaneously to identify gene alterations in the entire transcriptome across a variety of biological conditions. Combined with the whole rice genome sequences, gene function analysis, and comparative analysis of different genome sequences of crops, the entire genome transcriptional data will be the initial point for dissecting the molecular genetic mechanism of important complex agronomical traits in rice.

To achieve a more comprehensive understanding of the global spatial and temporal gene expression patterns of rice in response to drought stress, we performed a genome-wide gene profiling analysis using a unique drought tolerant rice line and an Affymetrix whole gene array set. Three tissues (i.e., leaf, young panicle, and root) at three developmental stages under drought stress and control conditions were used to profile their gene expression level. A temporal and spatial gene regulation pattern responsive to drought stress was primarily revealed in our study.

\section{Methods}

Plant materials, growth condition, and stress treatment

A drought tolerant rice line, DK151, an $\mathrm{F}_{7}$ line derived from a cross between two DT IR64 introgression lines (ILs), DGI 187 and DGI 74 (Additional file 1), was used in this study. Sterilized seeds of DK151 were allowed to germinate in distilled water for two days. The germinated seeds were then transferred to the seedling nursery. Rice plants at the four-leaf stage were transplanted in PVC tubes (size: $75 \mathrm{~cm} \times 20 \mathrm{~cm}$, each with a $20 \mathrm{~cm}$ hole from the bottom) with Turface (baked clay substrate mechanically broken into pieces with diameters of approximately $5 \mathrm{~mm}$ ) (Applied Industrial Materials, Corp., Buffalo Grove, IL, USA) and watered with alternate applications of half-strength nutrient solution [17] and distilled water. The experiment design was a split-plot with three blocks. Each treatment was represented by six replicate pots with one plant per pot. Pots were randomized within the blocks. This experiment was processed in the green house of IRRI in the 2007 dry season.

To simulate drought stress, plants of DK151 were stressed by slowly draining the solution. The hole plug of each tube was removed. We applied the stress at three different stages: 4-tiller (tillering) stage, panicle elongation stage, and booting stage. Plants were stressed until the leaf became fully rolled at noon (measured leaf relative water content was $65 \%-75 \%$ ). It took three and two days for drought stress to become apparent at the tillering and panicle elongation stages and at booting stage, respectively. Both leaf and root samples were collected for the first two stages, and leaves and young panicle samples were collected at the booting stage. Three biological replicates (each from individual plant) were prepared for microarray analysis. After collection, samples were snap frozen in liquid nitrogen and kept in a $-80^{\circ} \mathrm{C}$ freezer for total RNA extraction.

\section{Total RNA isolation, qualification, and processing for microarray analysis}

RNA preparation was conducted following the instructions of Affymetrix (Affymetrix GeneChip Expression Analysis Technical Manual, Affymetrix). Briefly total RNA was extracted from liquid nitrogen frozen sample using TRIZOL reagent according to the instruction, and then purified and concentrated using RNeasy MinElute Cleanup kit (Qiagen 74204, Germany) and an oncolumn DNase treatment as recommended by Affymetrix. The following steps were then processed in CapitalBio Corporation, Beijing. Total RNA of $2 \mu \mathrm{g}$ was used for synthesizing ds cDNA. Biotin-tagged cRNA was generated from an in vitro transcription reaction using MessageAmp TMII aRNA Amplification Kit and then fragmented into 35-200 bases in length according to the 
Affymetrix protocol. The resulting cRNA was then hybridized to the Affymetrix rice genome array (Affymetrix) containing 48,564 japonica and 1,260 indica sequences. Hybridization was processed at $45^{\circ} \mathrm{C}$, with rotation for $16 \mathrm{~h}$ (Affymetrix GeneChip Hybridization Oven 640). Chips were then washed and stained in the Affymetrix Fluidics Station 450 and then scanned using the Affymetrix Gene Chip Scanner 3000. All experiment steps were conducted in CapitalBio Corporation in Beijing.

\section{Array data analysis}

GeneChip Operating Software (GCOS1.4) was used to analyze the hybridization data. The scanned images were first examined by visual inspection and then processed to generate raw data saved as CEL files using the default setting of GCOS1.4. We used dChip software to perform invariant-set normalization according to the dChip user's manual. The whole set of original microarray data has been deposited in NCBI's Gene Expression Omnibus and can be freely accessed through GEO Series number GSE26280.

For comparison analysis, two classes of unpaired methods in the Significant Analysis of Microarray (SAM) software were applied to identify differentially expressed genes (DEGs) between the drought stress sample and the control sample. As there is no fixed standard threshold between significant and non-significant differential gene expressions, we identified the DEGs using the empirical criteria of more than five-fold change and significant $t$ test of $P$ value less than 0.05 based on three independent biological replicates. The DEGs were performed in complete linkage hierarchical clustering analysis using the TIGR MeV 4.2 software http://www.tm4.org.

\section{Functional classification and prediction of cis-acting regulatory elements for DEGs}

The putative function of each DEG corresponding to the probe set on the chip was predicted by Affymetrix annotation combined with TIGR definition and NCBI database. GO analysis was performed by a Molecule Annotation System (MAS, http://bioinfo.capitalbio.com/ mas/). Significance analysis of GO was performed by the gene enrichment based on hypergeometric distribution finished by Fisher or Chi-sequare test.

A Weeder program [18] was used to predict the cis regulatory elements for the DEGs set under drought stress. The gene sequences including the upstream were downloaded from the TIGR Web site for all selected DEGs. The shared motifs $6,8,10$, and $12 \mathrm{bp}$ in length (allowing one mismatch) and the known ABRE motifs were located in the promoter regions $(-10$ to $-1000 \mathrm{bp}$ upstream of the start codon) and compared with the promoter regions of all control genes $(P$-value $\leq 0.05)$.

\section{RT-PCR confirmation of candidate genes related to drought responsiveness}

Several genes with special tissue-specific or stage-specific DEGs were selected to confirm the expression level of microarray results using RT-PCR. The sequences corresponding to the genes were obtained from the rice genome sequences database (TIGR). The sequences of exons from genes were used to design the RT-PCR primers using the Primer 3 software http://frodo.wi.mit. edu/. An Actin gene was used as internal control. RTPCR-amplified products were sequenced, and 100\% homology to the target sequences was confirmed. PCR reaction was performed using the same RNA samples used for the microarray analysis. The first-strand cDNA was obtained from $1 \mu \mathrm{g}$ of total RNA in a $50 \mu \mathrm{l}$ reaction mixture, and $1 \mu$ l of synthesized cDNA was used as template for $\mathrm{PCR}$ reaction $\left(94^{\circ} \mathrm{C}\right.$ for $2 \mathrm{~min}$ and then 26 cycles of $30 \mathrm{~s}$ at $94^{\circ} \mathrm{C}, 30 \mathrm{~s}$ at $52^{\circ} \mathrm{C}$, and $30 \mathrm{~s}$ at $72^{\circ} \mathrm{C}$, followed by $72^{\circ} \mathrm{C}$ for $2 \mathrm{~min}$ ). All assays were performed in triplicate. After gel electrophoresis, we measured the intensity of each band and normalized the data using the beta actin bands of each well, respectively.

\section{Results and Discussion}

\section{Drought stress treatment and root sampling}

The objective of this study is to genome-wide profile the expression of genes in rice in a drought environment. To simulate natural growth conditions, rice plants were cultured in the glasshouse. Turface in the growth tubes was used to support plants for the easy and quick collection of root samples under drought treatment and control conditions. This simulated drought strategy is quite different from that previously used, such as hydroponic cultured in PEG solution [19] or air-drying [20] mixed clay soil with sand [21]. Plant roots play a vital role in water and mineral acquisition, and they are more sensitive to the change in soil environment. Under drought stress, roots can continue to grow and send the stress signal to the shoot. However, knowledge of gene expression and metabolic regulation in the root is limited because of the difficulty of the root sampling. There is no study yet on rice root under drought stress environment because of the difficulty of root sampling. Thus, our study offers the first comprehensive genome-wide gene profiling of drought responsiveness in the whole rice plant.

Identification and classification of drought-induced DEGs in different tissues at three developmental stages of rice Affymetrix whole rice genome array was used to profile the rice gene expression under drought and control 
conditions in this study. The array contains 49,824 rice genome genes/transcripts (48,564 and 1,260 for japonica and indica, respectively). Among these, 18,976 (38.1\%) to $23,068(46.4 \%)$ genes were detected to be expressed in each of the six samples under stressed or control environments (Additional file 2). We found most genes to be detectable in young panicle under control (46.5\%) and drought stress (46.1\%), and the least genes to be detectable in the leaf under control (38.1\%-39.2\%) and drought conditions (39.2\%-41.9\%).

To identify statistically significant DEGs under drought stress, we used the combined criteria of fivefold or more change and significant $t$ test of $P$ value of less than 0.05 based on three biological replicates. We detected the expression of 5,284 DEGs (10.6\%) in at least one of the six samples. A total of 1154, 878, 1114, 3283, 905, and 998 DEGs were found up- or down-regulated by drought in the samples of root at the tillering stage (TR), leaf at tillering stage (TL), root at panicle elongation stage (PR), leaf at panicle elongation (PL), young panicle sample at booting stage (BP), and leaf at booting stages (BL), respectively (Table 1$)$. In particular, most DEGs were identified in the leaf tissue during panicle elongation, the critical stage at which rice plants transit from the vegetative stage to the reproductive one, including 1316 drought-induced genes and 1967 drought-repressed genes, respectively.

In Figure 1, the detected 5,284 DEGs with known and putative function covered virtually all functional categories. The predominant DEGs were involved in response to stress including biotic and abiotic stimuli $(21.2 \%, q=4.33 \mathrm{E}-137)$, response to endogenous stimulus $(8.5 \%, q=2.43 \mathrm{E}-175)$, transcription regulation $(8.0 \%, q=0.005)$, metabolism such as lipid and carbohydrate metabolism $(9.3 \%, q=0.63)$, signal transcription $(7.1 \%, q=6.49 \mathrm{E}-102)$, and cell wall and membrane component $(18.9 \%, q=3.1 \mathrm{E}-70)$.

To investigate the similarities and differences of all DEGs among samples according to transcription levels, hierarchical complete linkage analysis was performed using TIGR MeV (Version 4.3, http://www.tm4.org/mev. html). Results show that the DEGs can be classified into several groups according to the expression pattern: the first group was the up-regulated gene set in at least one tissue; the second group was down-regulated gene set in at least one tissue; and the third group indicates the genes were specifically induced or repressed in one unique tissue (i.e., leaf, root, or panicle) under drought stress (Additional file 3).

To confirm the microarray profiling data, 24 genes were selected for semi-quantitative RT-PCR analysis. The gene specific primers are listed in Additional file 4 . Among these genes, there were 4, 14, and 6 with reciprocal action under drought from two tissues at the tillering stage, panicle elongation stage, and booting stage, respectively. There is good correlation between RT-PCR and microarray data in general. The expression pattern of several genes failed to confirm the microarray data because semi-quantitative RT-PCR examined the expression patterns of individual genes, as profiled by a single peak in the melting curve analysis. In the microarray analysis, no distinction was made between gene family members (Additional file 5).

\section{Comparison of DEGs in different tissues at three development stages}

We first compared the DEGs in the root or leaf tissues at different developmental stages. Venn diagram results indicate that a number of DEGs overlapped between leaves or between roots at different developmental stages. Figure 2A shows the comparison results of upor down-regulated genes in roots under drought stress at the tillering and panicle elongation stages. There were 299 and 404 genes commonly up- and down-regulated in roots by drought. A total of 92, 282 genes were induced and 359, 129 genes were repressed by drought exclusively in roots at the tillering and panicle elongation stages, respectively. Correspondingly, there was only a small portion of genes commonly regulated in leaves; 184 and 99 genes were detected to be commonly induced and repressed in all leaves at the three stages. Moreover, 60, 809, and 164 genes were induced, and 284,1547 , and 54 genes were peculiarly repressed by drought in leaves at the tillering, panicle elongation, and booting stages, respectively (Figure $2 \mathrm{~B}$ ).

Table 1 Summary of the genes up or down-regulated by drought stress in each tissue at different developmental stages

\begin{tabular}{lccc}
\hline Tissue & Up Regulated Genes & Down Regulated Genes & Sub-Total \\
\hline Root at tillering stage & 391 & 763 & 1154 \\
Leave at tillering stage & 320 & 558 & 878 \\
Root at panicle elongaiton stage & 581 & 533 & 1114 \\
Leave at panicle elongation stage & 1316 & 567 & 3283 \\
Panicle at booting stage & 351 & 354 & 905 \\
Leave at booting stage & 643 & 355 & 998 \\
\hline
\end{tabular}

Note: The DEGs were identified using the empirical criterion of more than five-fold change and significant $t$ tests of $P<0.05$ based on the three independent biological replicates. 


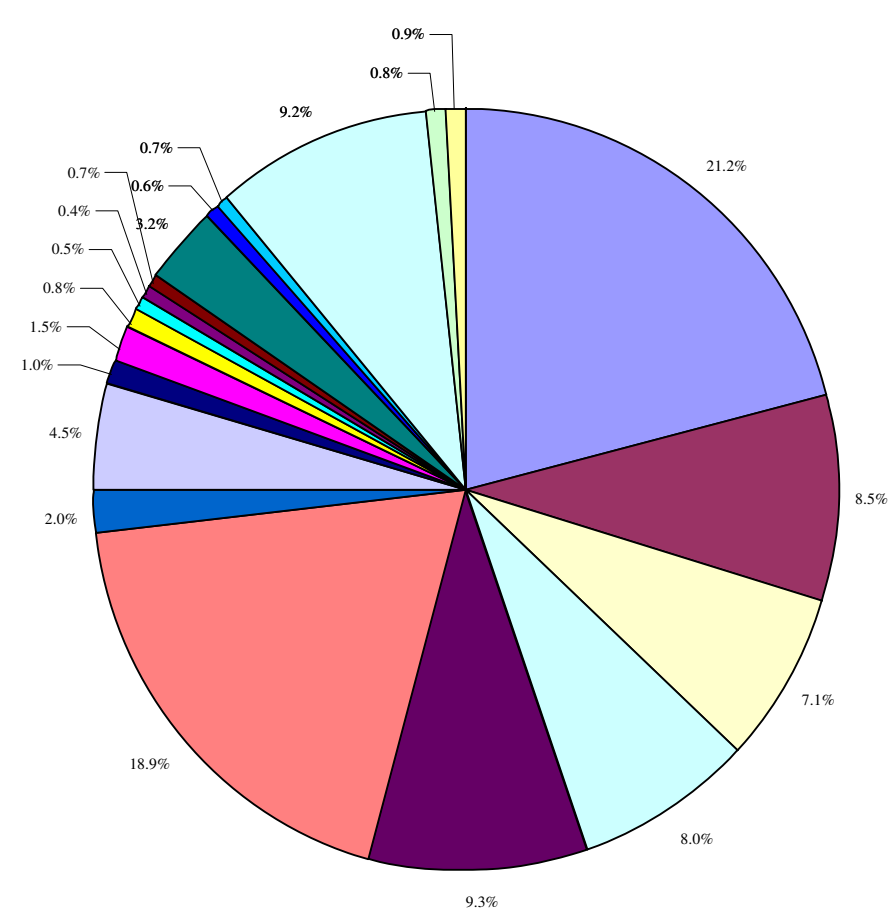
$\square$ Response to stress
$\square$ response to endogenous stimulus
$\square$ Signal transduction
$\square$ transcription regulation
Metabolism
$\square$ cell wall and membrane component
$\square$ Reproduction
$\square$ Biosynthesis
Development
$\square$ electron transport
$\square$ flower development
$\square$ cell organization and biogenesis
$\boldsymbol{\square}_{\text {protein biosynthesis }}$
$\boldsymbol{\square}$ protein modification
$\square$ transporter activity
D structural molecule activity
$\square_{\text {protein binding }}$
$\square$ nucleolus and nucleus
$\square$ extracellular region
$\square$ cytoplasmic membrane -bound vesicle

Figure 1 Function classification of all 5283 DEGs in at least one sample under drought stress

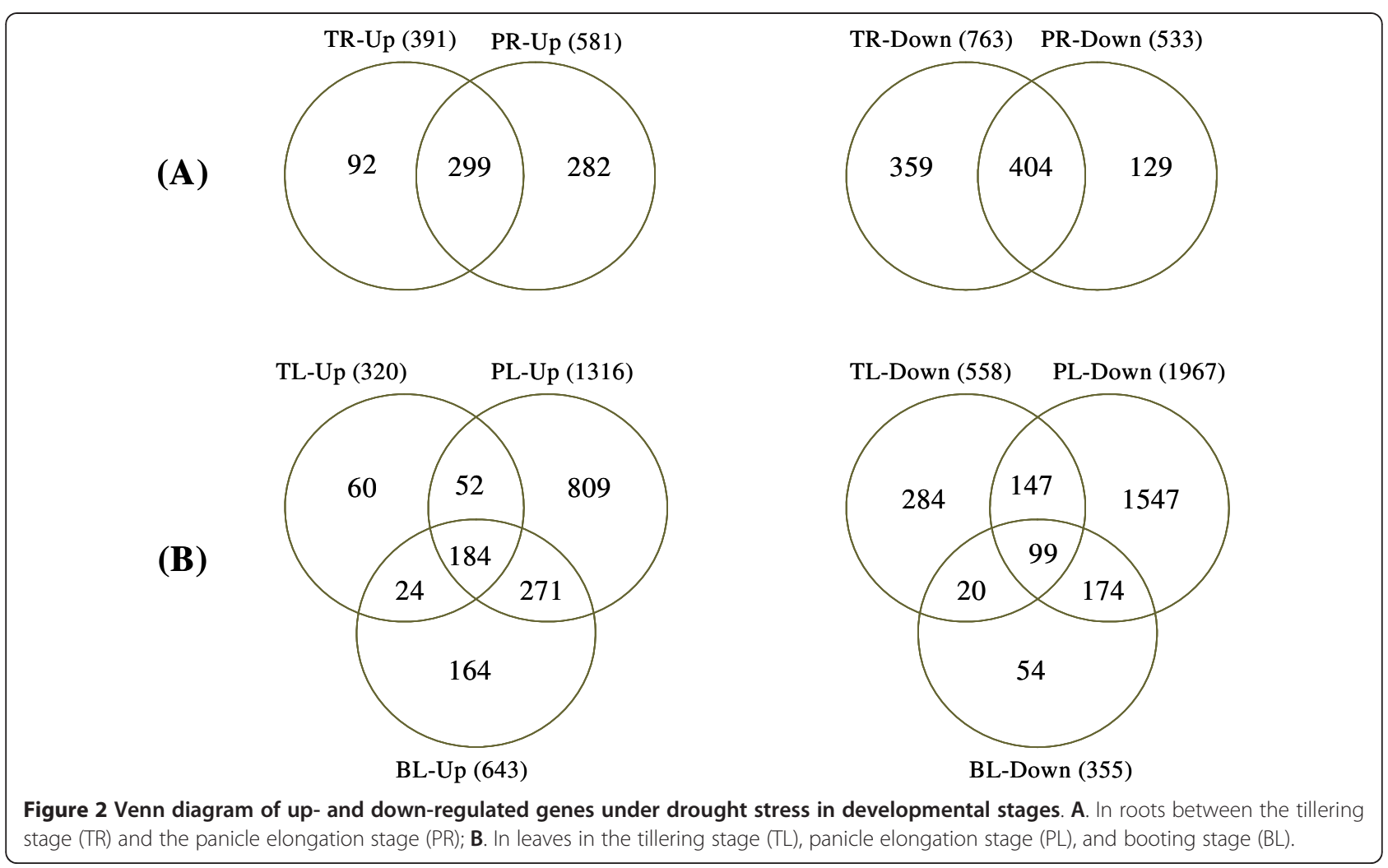


Stage-specific DEGs were also analyzed. There were only 121,279 , and 167 genes shared, which were upregulated by drought. A total of 58,81 , and 19 genes were commonly down-regulated between two tissues at the tillering, panicle elongation, and booting stages, respectively (Additional file 6). These results indicate that drought responsive genes in rice are highly dependent on the developmental stage and tissue type.

DEGs in all samples were further compared to screen the common up- or down-regulated genes by drought. We found a small set of genes commonly induced by drought stress in all tissues (Additional file 7). After removing the overlapping probes with the same gene accession number, 55 genes were identified (see Additional file 8), many of which also responded to other stresses, such as extreme temperature and salt $[13,14,16]$. There was a significant subset of common up-regulated genes $(n=7)$ identified as LEA proteins, four temperature-induced proteins (i.e., hsp70, lt101, cor14b, and another cold regulated protein), four dehydrin family proteins, and two protein phosphatase $2 \mathrm{C}$ family proteins, which were identified in a common induced gene set, involved in abiotic stress responsiveness. The others are related to amino acid and nucleotide metabolism, putative proteins, and proteins with unknown function.

Surprisingly, there was no gene detected as commonly repressed in all samples by the criterion of the five-fold change in our experiment. When the two-fold change criterion was adopted, only 20 genes were identified as commonly down-regulated in all tissues under drought stress (Additional file 9). Majority (12/20) of these sets of down-regulated genes were functionally classified into categories of cell wall extension or membrane metabolism, such as expansion, tubulin, transmembrane, and enzymes for the reorganization, division, and biosynthesis of cell wall.

\section{Unique functional categories of tissue-specific DEGs corresponding to their biological function}

To identify tissue- or stage-specific regulated genes from the 5,284 DEGs, the five-fold change in one surveyed target (tissue or stage) was required. However, this did not hold true in others. Tissue-specific DEGs were screened out using the following strategy: the genes with more than five-fold change only in the leaf tissues at the three development stages under drought were identified as the leaf specifically up- or down-regulated gene set; the specific DEGs in roots and panicle were also identified as those in leaves. Stage-specific DEGs were identified as genes with more than five-fold change in two tissues at one development stage only. After removing the redundancies of the probes, a total of 110 , 363 , and 448 tissue-specific DEGs were identified in leaf, root, and panicle, respectively (Figure 3, Table 2). More than three-quarters of the root-specific (286/363) and panicle-specific (346/448) DEGs were detected to be down-regulated under drought stress. We also detected 58 and 13 genes specifically induced by drought at the panicle elongation and booting stages, respectively, whereas two down-regulated specific genes were found at the panicle elongation stages. We could only identify three down-regulated genes under drought at the tillering stage, at which the rice plant is in the vegetative growth phase (Table 2).

To classify functionally the tissue- and stage-specific DEGs, gene ontology analysis was performed. Figure 4 shows some unique features for the individual tissuespecific DEGs, especially for the down-regulated gene sets. However, we could not find any unique function cluster for the stage-specific DEGs.

In leaves, the dominant categories of these specific DEGs were involved in metabolism, stress response, and transcription regulation, except that the products of one-third of the specific genes were putative proteins with unknown function. The 47 genes were determined to be specifically induced by drought in all leaves. Among them, four phytohormone-related genes were identified: ACC synthase (Os01g0192900), SDR protein (Os07g0664600) involved in ABA biosynthesis [22], IAA26 (Os01g0741900) responsive to IAA, and Auxin hydrogen symporter (Os09g31478) involved in Auxin

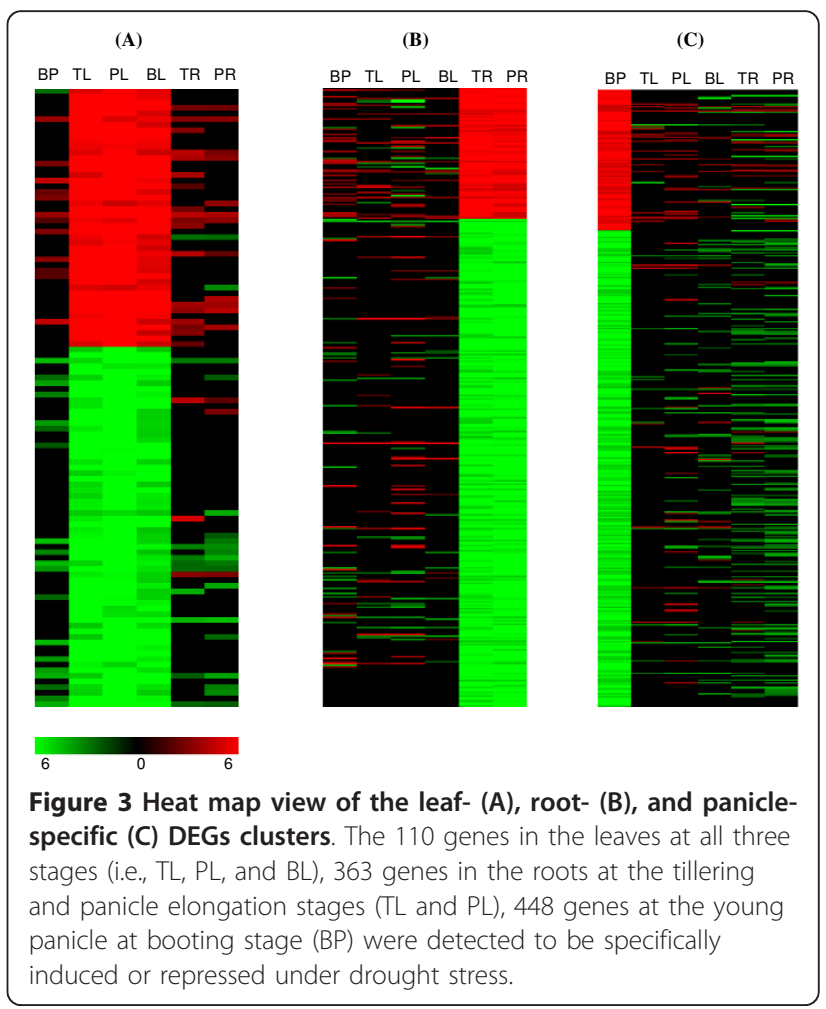


Table 2 List of tissue- and stage-specific up- and downregulated genes under drought stress

\begin{tabular}{lccc}
\hline Tissue/Stage & Up-regulated & Down-regulated & Subtotal \\
\hline Leaf & 46 & 64 & 110 \\
Root & 77 & 286 & 363 \\
Panicle & 102 & 346 & 448 \\
Tillering stage & 0 & 3 & 3 \\
Panicle elongation stage & 58 & 2 & 60 \\
Booting stage & 13 & 0 & 13 \\
\hline
\end{tabular}

polar transport (Additional file 10). Seven photosynthesis-related genes were uniquely down-regulated in all leaves in a drought environment (Additional file 11): chlorophyll a/b-binding protein CP24, photosystem I reaction center subunit $\mathrm{V}$, protochlorophyllide reductase A, peptidyl-prolyl cis-trans isomerase, and others functioning in the process of photosynthesis. ACC synthase gene encodes the enzyme to regulate the rate-limiting step in ethylene biosynthesis [23], and its expression regulates leaf performance and drought tolerance by increasing or decreasing the concentration of ethylene. The induced ACC synthase by drought resulted in retarded leaf growth under stress. The induced SDR, IAA 26, and auxin hydrogen symporter proteins could dynamically regulate the phytohormone (ABA, IAA, etc.) level to respond to drought stress. Seven genes involved in photosynthesis were specifically down-regulated in rice leaf. This result demonstrates that inhibition of photosynthesis is the major effect of drought responsiveness in rice leaf. Down-regulation of photosynthesis genes under a water deficit situation has been previously reported in rice and other crops $[24,25]$. The phytohormones of ABA, ethylene, and auxin are highly accumulated in leaf in a drought environment to maintain the homeostasis of plant biosynthesis.

A total of 76 genes were preferentially induced in the roots at the tillering and panicle elongation stages (Additional file 12), except for 35 genes with unknown function. A set of these genes were functionally involved in transcription regulation, such as those encoding one abscisic acid responsive elements-binding factor

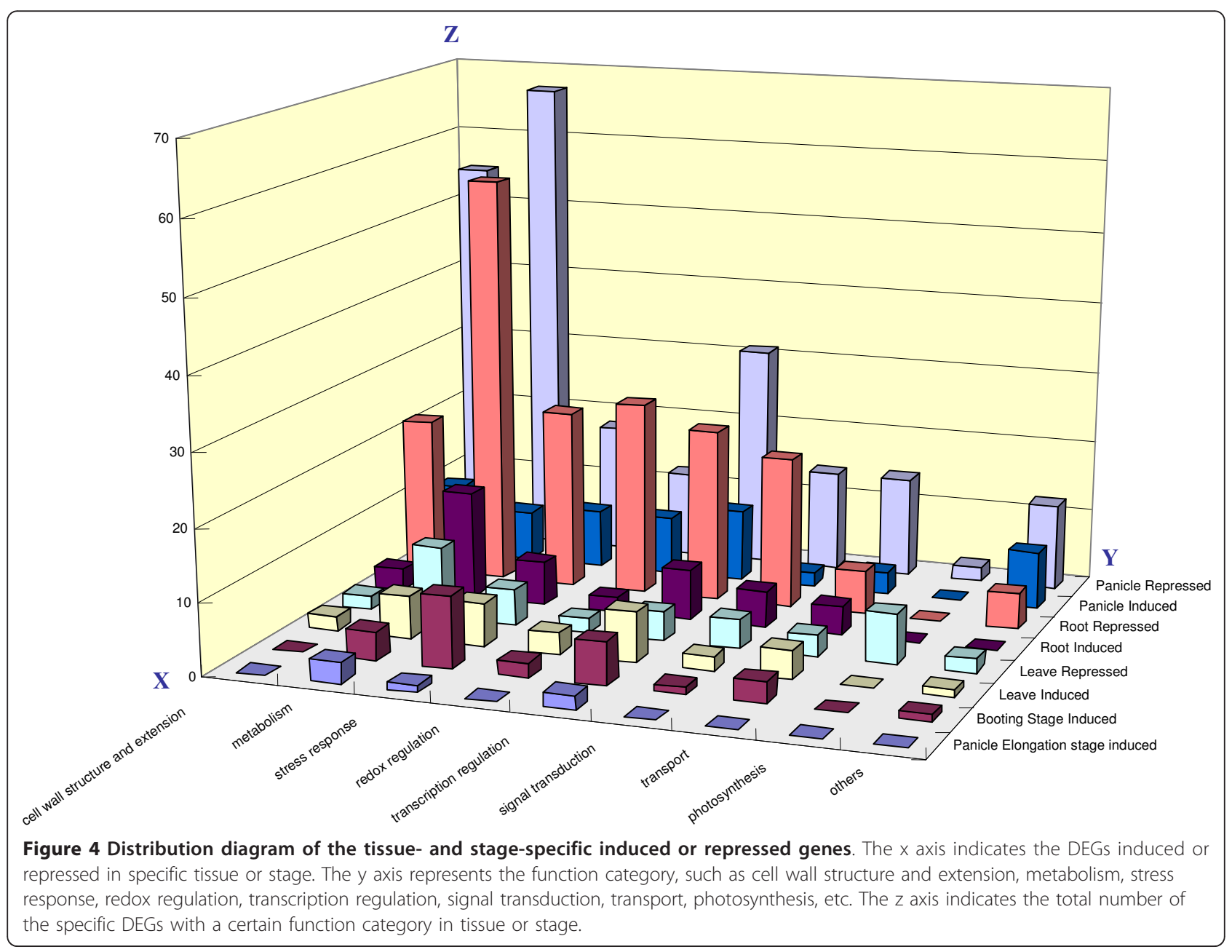


1 (AREB1, Os06g0211200), one heat shock transcription factor 31 (HSP31, Os02g0527300), two heat shock proteins (HSPs), three myb transcription factors, one bZip $\mathrm{TF}$, and three protein kinase including OsPK4 (Os01g0206300). All these were identified to be related to the upstream of gene regulation of drought or other abiotic stress responsiveness in plant. The gene AREB1 regulates novel ABRE-dependent ABA signaling that enhances plant drought tolerance in vegetative tissues [26].

A relatively large portion of the root-specific repressed genes is involved in metabolism, cell growth, cell wall modification, and phytohormone response (Additional file 13). Fourteen genes related to cell wall biogenesis and modification, such as the genes encoding three ENOD93 proteins, EXPA5, EXPA3, and one cell wall invertase (Os04g0664900), involved in the process of cell wall extension, were apparently down-regulated only in roots. Another root dependent repressed gene set is functionally related to phytohormone regulation. These genes encode four ethylene responsive transcription factors, namely, ER33, GAST1, Auxin efflux carrier protein (Os01g0802700), and GA2-oxidase (GA2ox, Os05g0560900), and two SDR family proteins (Os11g0499600, Os12g0260500). GAST1 gene was reported to be oppositely regulated by $\mathrm{GA}$ and $\mathrm{ABA}$, with $\mathrm{GA}$ inducing and $\mathrm{ABA}$ inhibiting its expression at the transcription level in a shoot of tomato [27]; the enzyme GA 2-oxidase antagonizes GA activity by deactivating GAs that regulate leaf expansion, stem elongation, and flower induction [28-30]. Therefore, GA might be promoted due to the down-regulation of GA2ox, whereas ethylene and Auxin were inhibited in root under drought. This finding reveals that root growth under drought is spatially regulated, whereas the response of root cell expansion to water stress is independently regulated in longitudinal and radial directions [31]. From these results, we can speculate that root elongation is enhanced under drought stress so that the stressed rice root can reach deeper water. However, the root may become thinner due to the inhibition of cell wall extension to save more energy to protect the rice plant from drought stress.

Specific drought DEGs were mostly detected in panicle among the three tissues. A total of 102 and 346 genes were identified to be up- and down-regulated specifically in panicle under drought, respectively (Additional files 14 and 15). First, several pollen or anther developmentrelated genes were identified to be particularly regulated by drought in rice panicle. Five genes encoding pollen allergen family proteins, profiling $\mathrm{A}$, and tapetum-specific endoxylanase were up-regulated, whereas another set of genes, such as gelsolin, anther-specific protein YY2, meiotic serine proteinase (Os04g0543700), two allergen V5/
Tpx-1 proteins, pistil-specific extension-like protein, plantacyanin, dioxygenase RAMOSUS1 (Os01g0566500), and CUT1 (Os01g0529800) were down-regulated by drought in the panicle only. Among these genes, gene encoding meiotic serine proteinase was significantly down-regulated more than 20 times by drought stress. This gene was found to be related to microsporogenesis. The gene RAMOSUS1 encodes dioxygenase and is involved in shoot branching [32], whereas the gene CUT1 encoding a very long chain of fatty acid condensing enzyme was identified to be related to cuticular wax biosynthesis and pollen development [33].

A total of 53 genes (53/346) related to membrane biogenesis and cell wall extension were confirmed to be exclusively down-regulated in young panicle (Additional file 15), although they belong to a different gene set from those down-regulated in root mentioned above. These genes encode cellulose synthase, lipid transfer proteins (LTPs), cell wall invertase, laccase, pectinesterase family proteins, and glycoside hydrolase family proteins. The cell wall invertases were involved in the panicle elongation, and their expression could be highly down-regulated by drought stress, resulting in the retardation of panicle elongation in rice [34]. LTPs, pectinesterases, and glycoside hydrolases are functionally related in membrane biogenesis and cell wall extension [35-37]. These results show that the panicle development of rice is greatly repressed when the rice plant is under the condition of water deficit.

Five histone genes were detected to be highly downregulated by drought exclusively in young panicle: Histone H2A (Os03g0162200), Histone H2A (Os03g0279200), Histone H3 (Os06g0160100), Histone H3 (Os05g0438700), and Histone H3 (Os01g0866200). These genes are involved in cell division and are reported to be regulated by drought and development $[38,39]$. However, the effect of the repression of histone genes on cell cycle in rice panicle under drought needs to be further elucidated.

Several genes showing reciprocal expression patterns in two tissues at the same development stage under drought were also identified. After comparing the whole gene profiling between two tissues at the same development stage, several genes were detected to be reciprocally regulated in two tissues under drought. At the tillering stage, 5 and 6 genes were induced and repressed in leaves but repressed and induced in roots, respectively. At the panicle elongation and booting stages, 29 and 4 genes were identified to be reciprocally regulated by drought in two different tissues, respectively (Table 3 ).

Three genes, i.e., GA2ox, Chitinase III, and Senescenceassociated protein 15 (SAP15), were highly induced in leaf but repressed in root at both the tillering and panicle elongation stages. GA2ox was highly down-regulated in all roots but up-regulated in all leaves and panicle. 
Table 3 List of genes with reciprocal action between two tissues at different development stages

\begin{tabular}{|c|c|c|c|c|c|c|c|}
\hline Gene ID & Annotation & BP & $\mathrm{BL}$ & PL & PR & TL & TR \\
\hline \multicolumn{8}{|c|}{ At Booting Stage } \\
\hline Os08g0547300 & E-class P450, group I family protein & 3.27 & -3.94 & -4.25 & & & \\
\hline Os07g0591700 & Conserved hypothetical protein & 2.50 & -3.35 & & & & \\
\hline Os07g0175600 & Plant lipid transfer protein & -2.71 & 2.51 & 3.34 & & & \\
\hline Os03g0793800 & Plant lipid transfer protein & -3.32 & 2.56 & & & & \\
\hline \multicolumn{8}{|c|}{ At Panicle Elongation Stage } \\
\hline Os05g0560900 & Gibberellin 2-oxidase & 2.75 & 5.02 & 3.07 & -5.20 & 3.30 & -4.82 \\
\hline Os11g0702100 & Class III chitinase homologue & & & 6.03 & -3.05 & 2.52 & -3.22 \\
\hline Os10g0158100 & Senescence-associated protein 15 & & & 2.79 & -3.37 & 2.34 & -4.26 \\
\hline Os04g0652700 & Nuclease I & & 3.61 & 3.98 & -2.60 & & -2.99 \\
\hline Os04g0635100 & Wound induced protein & & 4.06 & 3.29 & -3.08 & & \\
\hline Os03g0745200 & Transferase family protein & & & 3.03 & -2.49 & & -2.64 \\
\hline Os01g0788400 & Pectinesterase(Pectin methylesterase) & & & 3.33 & -2.71 & & -3.26 \\
\hline Os03g0830500 & PGPS/D12 & 4.44 & & 4.43 & -2.54 & & -5.23 \\
\hline Os12g0592900 & Hypothetical protein & & 2.98 & 5.15 & -3.43 & & -2.91 \\
\hline Os10g0418100 & Calcium-transporting ATPase 8 & & & 2.58 & -2.66 & & -2.86 \\
\hline Os04g0460300 & Amino acid/polyamine transporter ॥ & & 3.01 & 3.62 & -2.64 & & \\
\hline Os06g0592400 & Cytosolic aldehyde dehydrogenase RF2C & & & 3.06 & -3.05 & & -2.83 \\
\hline Os04g0268700 & Eggshell protein family protein & & & 2.62 & -4.15 & & -4.36 \\
\hline Os10g0464000 & Hypersensitive-induced response protein & & & 2.37 & -2.46 & & -3.28 \\
\hline Os02g0813100 & Cyclin-like F-box domain containing protein & & & 2.65 & -3.19 & & -3.06 \\
\hline Os01g0104200 & NAC-domain protein 5-8 & & & 3.23 & -2.46 & & -2.52 \\
\hline Os10g0391400 & ZIM domain containing protein & & & 2.76 & -3.89 & & -3.86 \\
\hline Os03g0100200 & Conserved hypothetical protein & & -2.33 & -4.35 & 3.02 & & \\
\hline Os09g0469300 & Plastocyanin-like domain containing protein & & & -2.56 & 5.44 & & 4.68 \\
\hline Os06g0136600 & Enolase 1 & & & -2.34 & 3.13 & & \\
\hline Os03g0178500 & Alpha/beta hydrolase family protein & & & -3.22 & 2.74 & -2.31 & \\
\hline Os04g0538000 & TPR repeat containing protein & & & -2.81 & 3.82 & & \\
\hline Os01g0279400 & Major facilitator superfamily antiporter & & -2.77 & -3.75 & 2.54 & -3.35 & \\
\hline Os01g0866400 & Fructose-1,6-bisphosphatase & & & -3.79 & 3.16 & & 3.22 \\
\hline Os01g0102300 & Conserved hypothetical protein & & & -3.64 & 4.00 & & 3.32 \\
\hline Os03g0197100 & Sugar transporter protein & & & -4.17 & 3.35 & & 4.56 \\
\hline Os12g0575000 & Protein of unknown function DUF1118 & & & -2.59 & 3.84 & & 3.93 \\
\hline Os01g0556700 & Dicarboxylate transporter & & & -2.65 & 5.13 & & 5.61 \\
\hline Os05g0568900 & Protease Do-like 1 & & & -2.39 & 3.10 & & \\
\hline \multicolumn{8}{|l|}{ At Tillering Stage } \\
\hline Os05g0560900 & Gibberellin 2-oxidase & 2.75 & 5.02 & 3.07 & -5.20 & 3.30 & -4.82 \\
\hline Os11g0702100 & Class III chitinase homologue & & & 6.03 & -3.05 & 2.52 & -3.22 \\
\hline Os10g0158100 & Senescence-associated protein 15 & & & 2.79 & -3.37 & 2.34 & -4.26 \\
\hline Os07g0127600 & Allergen $\mathrm{V} 5 / T p x-1$ related family protein & & & & -3.04 & 2.50 & -4.30 \\
\hline Os03g0322900 & Late embryogenesis abundant protein & 3.12 & 3.33 & 2.60 & 5.15 & -4.35 & 3.44 \\
\hline Os04g0685700 & Conserved hypothetical & & & & & -2.35 & 2.56 \\
\hline Os01g0946500 & Glucan endo-1,3-beta-glucosidase GV & 2.50 & & & 2.73 & -2.42 & 2.56 \\
\hline Os03g0625300 & Quinonprotein alcohol dehydrogenase & & & & 3.85 & -2.46 & 3.70 \\
\hline Os01g0789400 & Alpha subunit of RNA polymerase & & & & & -2.34 & 3.25 \\
\hline Os09g0402100 & PF1 protein & & & & & -4.08 & 2.94 \\
\hline
\end{tabular}

Note: Log2 transformed ratios of drought stress and control. 
One gene encoding the LEA protein (Os03g0322900) was only down-regulated in tillering leaf but up-regulated in all other tissues under drought. These results provide further evidence that the genes are regulated under environment stress in a tissue-specific manner. GA2ox has an important role in the regulation of stem elongation and leaf growth, and participates in the phase transition from vegetative to reproductive growth [40]. Induction of GA2ox may result in a low level of GA in leaf under drought by feedback control and retardation of leaf growth, whereas the GA2ox is highly repressed by drought. Senescence-associated proteins are involved in leaf senescence in plant [39]. The reciprocal regulation of SAP15 in root and leaf indicates that leaf growth was inhibited, whereas root growth was promoted by drought stress. The gene of Chitinase III confers disease resistance by degrading chitin, a component of fugal cell wall [41]. The biological role of this gene differently regulated by drought in root and leaf remains unclear.

Organ-/tissue-specific gene regulation in response to abiotic stresses has been previously reported. The gene encoding glutamine synthetase in potato was found to have a differential response to drought and salt stresses in an organ-dependent manner [42,43]. A systematic comparison of gene expression in various rice organs revealed mostly organ-specific reprogramming of genome expression responding to drought and high salinity [15]. These results support that each plant organ has a unique strategy in dealing with environmental stress.

\section{Genome-wide expression profiling of transcription factor (TF) genes under drought stress}

Among the 2384 known or annotated TF genes in the rice genome [44], 261 (10.9\%) TF genes were differentially regulated by drought (Additional file 16), accounting for about 5\% of total DEGs detected in this study. These TF genes belong to a diverse range of TF families classified by Gao et al. [44] including 35 MYB genes, 28 AP2/EREBP genes, 21 bHLH genes, 11 HSF genes, 27 NAC genes, 15 WRKY genes, etc. (Table 4). Among these TF genes, 153 were found to be differentially regulated by drought at the leaf of panicle elongation stage. After comparing the expression patterns of all TF genes, different sets of TFs genes with unique expression patterns were identified. Two TF genes encoding bZIP (OsbZIP14, Os01g0867300) and HB (Os02g0649300) proteins were commonly induced in all tissues at the three development stages, indicating that these two TF genes might be involved in the universal regulation of rice response to drought. OsbZIP14 was also found to be induced by drought in all tissues during panicle and seed development [45]. A total of 17 and 34 TF genes
Table 4 Drought-induced expression patterns of tissuespecific regulated AP2/EREBP transcription factors

\begin{tabular}{|c|c|c|c|c|c|c|c|}
\hline Gene ID & TF Family & TL & PL & $B L$ & TR & PR & BP \\
\hline Os08g0474000 & AP2/EREBP family & 4.16 & 4.05 & 3.81 & 3.44 & & 4.24 \\
\hline Os02g0764700 & AP2/EREBP family & 2.87 & 6.32 & 4.24 & & & 2.42 \\
\hline Os06g0166400 & AP2/EREBP family & & 3.12 & 3.34 & & & 3.14 \\
\hline Os02g0655200 & AP2/EREBP family & & 3.74 & 2.48 & & & \\
\hline Os06g0127100 & AP2/EREBP family & & 4.96 & 2.75 & & & \\
\hline Os01g0797600 & AP2/EREBP family & & & 2.34 & & & \\
\hline Os08g0537900 & AP2/EREBP family & & & 3.06 & & & \\
\hline Os04g0610400 & AP2/EREBP family & & & 2.97 & & & \\
\hline Os01g0165000 & AP2/EREBP family & & 4.68 & & & & \\
\hline Os09g0286600 & AP2/EREBP family & & 2.57 & & & & \\
\hline Os03g0183000 & AP2/EREBP family & & 3.68 & & & & \\
\hline Os04g0398000 & AP2/EREBP family & & 2.42 & & & & \\
\hline Os04g0546800 & AP2/EREBP family & & & & & & 3.59 \\
\hline Os05g0361700 & AP2/EREBP family & & & & 3.84 & 4.64 & 2.95 \\
\hline Os03g0182800 & AP2/EREBP family & & & & 4.06 & 3.84 & \\
\hline Os10g0390800 & AP2/EREBP family & & & & 2.64 & 2.74 & \\
\hline Os02g13710 & AP2/EREBP family & & & & 2.74 & 2.47 & \\
\hline Os07g0674800 & AP2/EREBP family & & & & 5.06 & 6.64 & \\
\hline Os04g0529100 & AP2/EREBP family & & & & 2.47 & 2.40 & \\
\hline Os01g0313300 & AP2/EREBP family & & & & 5.06 & 3.06 & \\
\hline Os03g0341000 & AP2/EREBP family & & & & 6.64 & 5.06 & \\
\hline Os03g0191900 & AP2/EREBP family & & & & & 2.84 & \\
\hline Os09g0522000 & AP2/EREBP family & & & & & 2.74 & \\
\hline Os12g0582900 & AP2/EREBP family & & & & 2.74 & & \\
\hline Os07g0617000 & AP2/EREBP family & & & & 2.56 & & \\
\hline Os09g0287000 & AP2/EREBP family & & & & 2.32 & & \\
\hline Os04g0550200 & AP2/EREBP family & 2.64 & & 2.74 & & & \\
\hline
\end{tabular}

Note: Log2 transformed ratios of drought stress and control.

shared the same expression pattern between two roots and among three leaves under drought, respectively. A total of 15, 13, and 21 TF genes were commonly regulated between two tissues at the tillering stage, panicle elongation stage, and booting stage, respectively. These results imply that only several TF genes of rice were coincidently regulated by drought stress.

Several of the TF genes were tissue- or stage-specifically regulated, especially the plant-specific TF gene family member. The 10 identified HSF genes were highly up-regulated in at least one tissue, 9 of which were induced in the root at the panicle elongation stage. Five members of the GRAS family genes were down-regulated in root or leaf. The three auxin responsive or ARF genes were exclusively repressed in leaf at the panicle elongation stage. Most of the identified bHLH genes (18 out of 21) were found to be down-regulated in either at least one root tissue or one leaf tissue (Additional file 17). These differentially expressed bHLH TF genes were further functionally identified in an experiment of PEGsimulated drought stress and exogenous ABA treatment 
using quantitative RT-PCR analysis [46]. Result also show that most of the bHLH genes were repressed in seedling roots and leaves under PEG stress and ABA stress [46], implying that these bHLH genes might have negative roles in rice responding to osmotic stress.

As for stage-specific regulated TF genes, three of them, including one ZIP member and two MYB, were down-regulated only at the tillering stage. Nine TF genes were only differentially regulated (the same or different pattern) by drought at booting stage. A total of $25 \mathrm{TF}$ genes belonging to bHLH, GRAP-G2-like, MYB, NAC, and ZIM families were only differentially regulated (the same or different pattern in two tissues) by drought at the panicle elongation stage. There were 7 and 7 MYB and NAC genes induced by drought exclusively in leaf at panicle elongation stage, respectively (Additional file 16). A number of NAC TF genes and several MYB TF genes have been previously found to be differentially expressed in a tissue-specific manner under various abiotic stresses, such high salinity, cold stress, and drought environment [47-49]. This stage-specific gene profiling of TF genes implies that drought stress responsiveness is under developmental control.

AP2/EREBP family proteins are unique to plants and share a highly conserved AP2 domain. Several AP2/ EREBP TF genes were involved in transcriptional regulation pathway of ABA-dependent and ABA-independent response to drought stress [50,51]. Two distinct sets of AP2/EREBP transcription factor members were determined in this study. One set of the TFs, including 14 members, was specifically induced by drought in at least one leaf tissue or panicle, except for one, AP2/EREBP TF, which was repressed in TL and BL. Another set of $13 \mathrm{TF}$ genes were repressed only in root, mostly in root samples from both stages, except for one gene that was reciprocally regulated in roots and panicle (Table 4). These results show that AP2/EREBP TF genes are highly under organ-specific regulation by drought. These results were also confirmed by the macroarray analysis of AP2/EREBP TF genes family and RT-PCR analysis of drought differentially regulated TF genes [52].

AP2/EREBP TF genes play an important role in regulating developmental processes. Several of these genes have been identified to be functionally involved in developmental control, such as APETALA in identity with the Arabidopsis flower [53], and AINTEGUMENTA and AINTEGUMENTALIKE6 in flower patterning [54], PUCHI affecting root morphogenesis [55]. These organdependent regulations of AP2/EREBP TF genes might be responsible for regulating organ-specific downstream genes in response to drought stress.

The rice genome has more than $2000 \mathrm{TF}$ genes [44], majority of which are members of large families. In this study, $261 \mathrm{TF}$ genes were found to be differentially regulated by drought, and most TF genes were tissueor stage-specific regulated. This finding implies that these TF genes can play different roles in the regulation of rice plant response to drought stress and that the regulation may be under the control of development.

\section{Regulatory element analysis of commonly induced genes under drought stress}

To identify common sequence motifs of drought-induced genes in rice, we examined the cis-regulatory elements in the $1 \mathrm{~kb}$ regions upstream of 55 commonly induced genes in all tissues using two approaches. First, all known cis-elements responsive to drought were used as targets to scan the upstream sequences. The other method used was not based on known elements, in that all possible 6-meric, 8-meric, 10-meric, and 12-meric sequences were evaluated for whether they are overrepresented in the scanned regions using the Weeder software.

Four ABA responsive elements (ABRE) containing an ACGT core sequence (i.e., RTACGTGGCR, ACGTSSSC, TACGTGTC, and ACGTGKC) were used to search the upstream of the 55 genes with the control upstream sequences of 360 genes showing no significant change in expression pattern under drought. We found four elements over-represented in the commonly induced 55 genes compared with the control. A total of $72.7 \%$ of the genes contain 1-8 copies of the 4 ABREs, whereas only $3.6 \%$ of the control genes harbor 1-3 copies of the elements. Another ABRE motif, S000278 with ACGT core sequence, was also significantly detected to be overpresented in the 55 genes. Around $31.5 \%$ of the genes have at least one copy of S000278, whereas only $0.83 \%$ of the control genes have the sequence(s).

All $1 \mathrm{~kb}$ sequences in the upstream of the 55 genes were submitted to a local installation of Weeder (version 1.3 ) and an extra mode search (6 bp long with 1 mismatch; 8 bp long with 3 mismatches; 10 bp long with 4 mismatches, and 12 bp long with 4 mismatches) was performed to look for the candidate motifs in a single strand. Four GC-rich sequences, namely, 6 bp of CCGCGC, 8 bp of CGCCGCGC, 10 bp of GCCGCGCG GC, and 12 bp of GCCGCGCCGCGC, were identified. The motif sequence logo is available in the supplementary material (Additional file 18). Most of these four motifs were located between -10 and $-500 \mathrm{bp}$ apart from the start codon, but majority of them were in the upstream region from -100 to $-300 \mathrm{bp}$. In total, 48 and 41 out of the 55 genes have at least one or two copies of the four elements (Table 5). CGCG box was identified among these cis-elements after further analysis; this special CGCG box is regulated by calmodulin and involved in the transcription regulation of multiple abiotic stresses responsiveness [56]. A number of GC rich motifs with a 
Table 5 Copy number of the four cis-elements identified in the upstream regions of 55 commonly induced genes

\begin{tabular}{|c|c|c|c|c|c|c|}
\hline No & Gene ID & Annotation & S1 & S2 & S3 & S4 \\
\hline 1 & Os08g0104400 & expressed protein & 1 & & & \\
\hline 2 & Os01g0705200 & late embryogenesis abundant protein 3 & 8 & 3 & 4 & \\
\hline 3 & Os12g0478200 & ABA-responsive protein & 2 & & & \\
\hline 4 & Os03g0305600 & expressed protein & 3 & 1 & & \\
\hline 5 & Os01g0225600 & late embryogenesis abundant protein Lea14-A & 2 & 1 & & \\
\hline 6 & Os09g0109600 & expressed protein & 1 & & & \\
\hline 7 & Os05g0542500 & late embryogenesis abundant protein 3 & 4 & 1 & & \\
\hline 8 & Os11g0454300 & water stress-inducible protein Rab21 & 8 & 3 & & 1 \\
\hline 9 & Os02g0140800 & expressed protein & 1 & & 1 & \\
\hline 10 & Os01g0214500 & conserved hypothetical protein & 5 & 2 & 2 & \\
\hline 11 & Os04g0266900 & transketolase, chloroplast precursor & 5 & 1 & 2 & \\
\hline 12 & Os01g0124400 & Bowman-Birk type bran trypsin inhibitor precursor & 1 & & 1 & \\
\hline 13 & Os11g0582300 & protein SEY1 & 7 & 1 & 1 & 1 \\
\hline 14 & Os07g0563400 & fiber expressed protein, putative, expressed & 7 & 5 & 2 & \\
\hline 15 & Os10g0548100 & expressed protein & 17 & 9 & 5 & 5 \\
\hline 16 & Os01g0226400 & ATP binding protein, putative, expressed & 8 & 7 & 3 & 2 \\
\hline 17 & Os06g0698300 & protein phosphatase $2 \mathrm{C}$ & 12 & 3 & & 1 \\
\hline 18 & Os01g0867300 & G-box-binding factor 4 & 4 & 2 & 3 & 1 \\
\hline 19 & Os01g0654400 & seed maturation protein PM41 & 4 & 1 & 2 & \\
\hline 20 & Os10g0505900 & expressed protein & 5 & & 1 & \\
\hline 21 & Os01g0743500 & NADP-dependent malic enzyme & 11 & 4 & 3 & 1 \\
\hline 22 & Os02g0649300 & homeobox-leucine zipper protein ATHB-6 & 7 & 1 & 1 & \\
\hline 23 & Os01g0950900 & HYP1 & 16 & 8 & 8 & 3 \\
\hline 24 & Os06g0324400 & protein LEA25 & 1 & & & \\
\hline 25 & Os03g0133100 & expressed protein & 13 & 5 & 1 & 3 \\
\hline 26 & Os05g0572700 & protein phosphatase $2 \mathrm{C}$ ABI1 & 21 & 9 & 3 & 2 \\
\hline 27 & Os11g0454200 & dehydrin Rab16B & 2 & 1 & 1 & \\
\hline 28 & Os12g0147200 & expressed protein & 7 & 3 & 2 & 2 \\
\hline 29 & Os03g0623100 & expressed protein & 4 & 3 & & \\
\hline 30 & Os05g0373900 & eukaryotic peptide chain release factor subunit 1-1 & 5 & 1 & & \\
\hline 31 & Os11g0454000 & dehydrin Rab16C & 1 & & & \\
\hline 32 & Os08g0327700 & seed maturation protein & 5 & 2 & 1 & \\
\hline 33 & Os04g0610600 & embryonic protein DC-8 & 10 & 4 & 3 & 2 \\
\hline 34 & Os06g0246500 & pyruvate dehydrogenase E1 component alpha subunit & 17 & 5 & 3 & 3 \\
\hline 35 & Os01g0844300 & FK506-binding protein 4 & 4 & 2 & 1 & \\
\hline 36 & Os03g0723400 & expressed protein & 1 & & & \\
\hline 37 & Os06g0341300 & late embryogenesis abundant protein D-34 & 7 & 1 & & \\
\hline 38 & Os06g0681200 & early nodulin 20 precursor & 2 & 1 & & \\
\hline 39 & Os08g0442900 & fibroin heavy chain precursor & 5 & 2 & 1 & \\
\hline 40 & Os05g0550600 & nonspecific lipid-transfer protein AKCS9 precursor & 14 & 4 & 5 & 1 \\
\hline 41 & Os03g0168100 & embryonic protein DC-8 & 7 & 3 & 1 & \\
\hline 42 & Os03g0168000 & expressed protein & 9 & 5 & 2 & 1 \\
\hline 43 & Os04g0589800 & seed maturation protein & 6 & 5 & 2 & 3 \\
\hline 44 & Os01g0794400 & protein disulfide isomerase, putative, expressed & 2 & 1 & & 1 \\
\hline 45 & Os06g0651200 & expressed protein & 6 & & & \\
\hline 46 & Os11g0453900 & dehydrin Rab16D & 9 & 3 & 1 & 1 \\
\hline 47 & Os01g0303300 & stress-inducible membrane pore protein & 13 & 1 & 1 & \\
\hline 48 & Os05g0468800 & expressed protein & 12 & 7 & 3 & 2 \\
\hline 49 & Os11g32890 & expressed protein & & & & \\
\hline 50 & Os03g0277300 & heat shock cognate $70 \mathrm{kDa}$ protein & & & & \\
\hline 51 & Os05g0122700 & expressed protein & & & & \\
\hline
\end{tabular}


Table 5 Copy number of the four cis-elements identified in the upstream regions of $\mathbf{5 5}$ commonly induced genes (Continued)

\begin{tabular}{lll}
\hline 52 & Os11g0181200 & expressed protein \\
53 & Os11g43790 & expressed protein \\
54 & Os03g0286900 & expressed protein \\
55 & Os01g0743600 & ATP-dependent peptidase \\
\hline
\end{tabular}

Note: Log2 transformed ratios of drought stress and control.

core motif of CGCG have been identified to be significantly over-represented in the promoter of the physcomitrella ABA- and stress-induced gene set [57]. This special CGCG box combined with the ABRE element may be very important for the response of the rice plant to drought environment.

\section{Conclusion}

A systematic study of gene profiling of rice genome in response to drought stress was carried out using the Affymetrix rice genome array containing 49,824 known or predicted genes. In this study, three main rice tissues including leaf, root, and young panicle from three development stages were sampled for array analysis. This is the first trial to explore comprehensively the genomewide gene spatial and temporal expression patterns of drought responsiveness in rice. Results show that most drought-responsive genes were under tissue- and stagespecific regulations.

We detected 5,284 transcripts/genes differentially expressed under drought stress, accounting for around $10 \%$ of total transcripts on the rice array chips. Only a small amount of genes was identified to be commonly upregulated by drought in all tissues at three development stages. Most of the DEGs were tissue-specific regulated by drought. Notably, the tissue-specific down-regulated genes showed distinct function categories. Several genes related to photosynthesis were identified to be specifically repressed by drought in leaf. However, a large amount of genes involved in cell membrane biogenesis and cell wall modification was determined to be highly down-regulated, specifically in root and young panicle. We may conclude that photosynthesis in the leaf, panicle elongation, and root growth is significantly inhibited by drought when rice plant is in a water deficit situation.

There was strong interaction between plant development and environment conditions. Plant stress responses often mimic certain normal developmental processes. There was also evidence that systematic regulation of gene expression drives developmental processes and stress response [58,59]. Some stage- or tissue-specific regulated genes are likely to be co-regulated by environment stresses and development cues, and the rice plant response to drought appears to be under developmental regulation.
Transcription regulation plays a central role in stress signal transduction pathways. In this study, we found 261 transcription factor genes differentially regulated at different levels in root, leaf, and young panicle at different development stages. Among these, 153 TF genes were found to be up- or down-regulated in the leaf at the panicle elongation stage. This finding reveals that a large amount of TF genes is involved in the transcription regulation in response to drought stress when rice plant is at the panicle elongation stage.

Numerous cis-elements have been previously reported to be important in plant response to drought stress, including ABRE and DRE-like elements, which are the binding sites for bZIP and AP2/EREBP-type transcription factors. Except for the prevalence of ABRE element in the upstream of commonly induced 55 genes in this study, a CGCG box motif was also found to be a probable candidate in cis-element for the transcription regulation of drought responsiveness in rice. However, whether this element functions as a transcription factor binding site needs to be further determined.

\section{Additional material}

Additional file 1: Pedigree of the variety DK151. A word file containing the BC breeding and intercross procedures for developing drought tolerant introgression lines and pyramiding line, DK151 using IR64 (the recipient) and two donors, BR24 and Binam.

Additional file 2: Total number of genes expressed in different samples under control and drought stressed conditions. Excel file containing the summary result of expressed gene number in different samples.

Additional file 3: Hierarchical cluster analysis of six tissue types and all DEGs under drought stress. PPT file containing the result of the hierarchical cluster analysis.

Additional file 4: List of primers for the RT-PCR. Excel file containing all primer sequences used for the RT-PCR experiment.

Additional file 5: Semi-quantitative RT-PCR confirmation of microarray data. Description: A ppt file containing semi-quantitative RTPCR confirmation of microarray data. The microarray data are shown on the left side, and the RT-PCR results are shown on the right side. A total of 21 genes were differentially regulated by drought at the tillering stage, panicle elongation stage, and booting stage. TLC and TLS indicate leaves under control and under stress, and TRC and TRS indicate root under control and stress at the tillering stage, respectively. PLC and PLS indicate leaves under control and stress, and PRC and PRS indicate root under control and stress at the panicle elongation stage, respectively. BLC and BLS indicate leaves under control and stress, and BPC and BPS indicate panicle under control and stress at the booting stage, respectively. 
Additional file 6: Comparative diagram of the tissue-specific DEGs under drought stress. A ppt file containing a comparative diagram of the total number of up-, down-regulated, and common regulated genes between leaves and root at the tillering stage $(T L, T R)$, leaves and root at the panicle elongation stage (PL, PR), and leaves and panicle at the booting stage (BL, BP) under drought stress.

Additional file 7: Venn diagram of all tissue up- and downregulated DEGs under drought stress. PPT file for the result of Venn Diagram of all tissue-specific DEGs.

Additional file 8: List of commonly induced genes by drought in all tissues at all development stages. Excel file containing the list of the commonly induced genes in all samples.

Additional file 9: List of commonly down-regulated genes by drought in all tissues at all development stages. Excel file containing the list of the commonly down-regulated genes in all samples.

Additional file 10: Leaf specific up-regulated genes under drought stress. Excel file containing all specific up-regulated genes by drought in leaf.

Additional file 11: Leaf specific down-regulated genes under drought stress. Excel file containing all specific down-regulated genes by drought in leaf.

Additional file 12: Root-specific up-regulated genes under drought stress. Excel file containing all specific up-regulated genes by drought in roots.

Additional file 13: Root-specific down-regulated genes under drought stress. Excel file containing all specific down-regulated genes by drought in roots.

Additional file 14: Panicle-specific up-regulated genes under drought stress. Excel file containing all specific up-regulated genes by drought in panicle.

Additional file 15: Panicle-specific down-regulated genes under drought stress. Excel file containing all specific down-regulated genes by drought in panicle.

Additional file 16: List of TF genes differentially regulated under drought stress. Excel file containing all transcription factor genes differentially regulated by drought stress in all samples.

Additional file 17: List of TF gene stages specifically regulated by drought stress. Excel file of the identified transcription factor genes specifically regulated by drought stress.

Additional file 18: Sequence Logo of the core sequences of the identified four motifs. A PPT file of the sequence logo of the core sequences of the identified motifs.

\section{Acknowledgements}

This study was supported by the Key Project from Ministry of Agriculture (Grant No. 2008ZX001-003 and 2009ZX08009-007B), the National 973 project of the Chinese Ministry of Science and Technology (Grant No. 2003CB114308 to ZL), and a grant (\#2005 FS029) from the Rockefeller Foundation to ZL.

\section{Author details}

'Institute of Crop Sciences/National Key Facility for Crop Gene Resources and Genetic Improvement, Chinese Academy of Agricultural Sciences, Beijing 100081, China. ${ }^{2}$ College of Life Sciences and Technology, Shenyang Agriculture University, Shenyang 110161, China. International Rice Research Institute, DAPO Box 7777, Metro Manila, Philippines.

\section{Authors' contributions}

$\mathrm{BF}$ and $\mathrm{ZL}$ designed the experiments and drafted the manuscript. DW, YP, $X Z$, and $L Z$ performed the phenotypic experiment and the microarray experiment. BF designed the microarray experiments, performed the data analyses of microarray, and revised the manuscript. All authors have read and approved the final manuscript.
Received: 28 June 2010 Accepted: 16 March 2011

Published: 16 March 2011

\section{References}

1. Datta SK, Malabuyac JA, Aragon EL: A field screening technique for evaluating rice germplasm for drought tolerance during the vegetative stage. Field Crops Res 1988, 19:123-13.

2. Jiang $X L$, Zheng JG, Yuan $Y$ : Effects of water stresses on grain yield at different rice growth stage. Southwest China Journal of Agricultural Sciences 2004, 4:435-438.

3. Mitra J: Genetics and genetic improvement of drought resistance in crop plants. Current Sciences 2001, 80:758-763.

4. Li ZK, Fu BY, Gao YM, Xu JL, Ali J, Lafitte HR, Jiang YZ, Rey JD, Vijayakumar CHM, Maghirang R, Zheng TQ, Zhu LH: Genome-wide introgression lines and their use in genetic and molecular dissection of complex phenotypes in rice (Oryza sativa L.). Plant Molecular Biology 2005, 59:33-52.

5. Courtois B, Shen L, Petalcorin W, Carandang S, Mauleon R, Li Z: Locating QTLs controlling constitutive root traits in the rice population IAC $165 \mathrm{x}$ Co39. Euphytica 2003, 134:335-345.

6. Tripathy JN, Zhang J, Robin S, Nguyen TT, Nguyen HT: QTLs for cellmembrane stability mapped in rice (Oryza sativa L.) under drought stress. Theoretical and Applied Genetics 2000, 100:1197-1202.

7. Lilley JM, Ludlow MM, McCouch SR, OToole JC: Locating QTL for osmotic adjustment and dehydration tolerance in rice. Journal of Experimental Botany 1996, 47:1427-1436.

8. Bartels D, Sunkars R: Drought and salt tolerance in plants. Critical Reviews in Plant Science 2005, 24:23-58.

9. Umezawa T, Fujita M, Fujita Y, Yamaguchi-Shinozaki K, Shinozaki K: Engineering drought tolerance in plants: discovering and tailoring genes unlock the future. Current Opinion in Biotechnology 2006, 17:113-122.

10. Chao DY, Luo YH, Shi M, Luo D, Lin HX: Salt-responsive genes in rice revealed by cDNA microarray analysis. Cell Research 2005, 15:796-810.

11. Lan LF, Li MN, Lai Y, Xu WY, Kong ZS, Ying K, Han B, Xue YB: Microarray analysis reveals similarities and variations in genetic programs involved in pollination/fertilization and stress responses in rice (Oryza sativa L.). Plant Molecular Biology 2005, 59:151-164

12. Furutani I, Sukegawa S, Kyozuka J: Genome-wide analysis of spatial and temporal gene expression in rice panicle development. The Plant Journal 2006, 46:503-511.

13. Walia $H$, Wilson C, Condamine $P$, Liu X, Ismail AM, Zeng LH, Wanamaker SI, Mandal J, Xu J, Cui XP, Close TJ: Comparative transcriptional profiling of two contrasting rice genotypes under salinity stress during the vegetative growth stage. Plant Physiology 2005, 139:822-835.

14. Walia H, Wilson C, Zeng LH, Ismail A, Condamine P, Close T: Genome-wide transcriptional analysis of salinity stressed japonica and indica rice genotypes during panicle initiation stage. Plant Molecular Biology 2007, 63:609-623.

15. Zhou J, Wang X, Jiao Y, Qin Y, Liu X, He K, Chen C, Ma L, Wang J, Xiong L Zhang $Q$, Fan L, Deng XW: Global genome expression analysis of rice in response to drought and high-salinity stresses in shoot, flag leaf, and panicle. Plant Mol Biol 2007, 63:591-608.

16. Yamakawa H, Hirose T, Kuroda M, and Yamaguchi T: Comprehensive expression profiling of rice grain filling-related genes under high temperature using DNA microarray. Plant Physiology 2007, 144:258-277.

17. Yoshida S, Forno DA, Cock JH, Gomez KA: Laboratory manual for physiological studies of rice. Los Banõs, Laguna, Philippines. Third edition. International Rice Research Institute; 1976.

18. Pavesi G, Mereghetti P, Mauri G, Pesole G: Weeder Web: Discovery of transcription factor binding sites in a set of sequences from coregulated genes. Nucleic Acids Research 2004, 32:W199-W203.

19. Fu BY, Xiong JH, Zhu LH, Zhao XQ, Xu HX, Gao YM, Li YS, Xu JL, Li ZK: Identification of functional candidate genes for drought tolerance in rice. Mol Genet Genomics 2007, 278:599-609.

20. Zhou Y, Lam HM, Zhang J: Inhibition of photosynthesis and energy dissipation induced by water and high light stresses in rice. Journal of Experimental Botany 2007, 58:1207-17.

21. Yue B, Xue W, Xiong L, Yu X, Luo L, Cui K, Jin D, Xing Y, Zhang Q: Genetic basis of drought resistance at reproductive stage in rice: separation of drought tolerance from drought avoidance. Genetics 2006, 172:1213-28. 
22. Seo M, Koshiba T: Complex regulation of ABA biosynthesis in plants. Trends in Plant Science 2002, 7:41-48.

23. Young TE, Meeley RB, Gallie DR: ACC synthase expression regulates leaf performance and drought tolerance in maize. Plant J 2004, 40:813-25.

24. Ozturk ZN, Talame V, Deyholos M, Michalowski CB, Galbraith DW, Gozukirmizi N, Tuberosa R, Bohnert HJ: Monitoring largescale changes in transcript abundance in drought- and salt stressed barley. Plant Mol Biol 2002, 48:551-573.

25. Hazen SP, Pathan MS, Sanchez A, Baxter I, Dunn M, Estes B, Chang HS, Zhu T, Kreps JA, Nguyen HT: Expression profiling of rice segregating for drought tolerance QTLs using a rice genome array. Funct Integr Genomics 2005, 5:104-116.

26. Fujita Y, Fujita M, Satoha R, Maruyama K, Parvez MM, Seki M, Hiratsu K, Ohme-Takagi M, Shinozaki K, Yamaguchi-Shinozaki K: AREB1 is a transcription activator of novel ABRE-dependent ABA signaling that enhances drought stress tolerance in Arabidopsis. The Plant Cell 2005, 17:3470-3488.

27. Shi L, Olszewski NE: Gibberellin and abscisic acid regulate gastl expression at the level of transcription. Plant Mol Biol 1998, 38:1053-1060.

28. Weiss $\mathrm{D}$, Ori N: Mechanisms of cross talk between gibberellin and other hormones. Plant Physiol 2007, 144(3):1240-6.

29. Lo SF, Yang SY, Chen KT, Hsing YI, Zeevaart JA, Chen LJ, Yu SM: A novel class of gibberellin 2-oxidases control semidwarfism, tillering, and root development in rice. Plant Cell 2008, 20(10):2603-18.

30. Sun TP: Gibberellin-GID1-DELLA: A pivotal regulatory module for plant growth and development. Plant Physiology 2010, 154:567-570.

31. Sharp RE, Poroyko V, Hejlek LG, Spollen WG, Springer GK, Bohnert HJ, Nguyen HT: Root growth maintenance during water deficits: physiology to functional genomics. Journal of Experimental Botany 2004, 55:2343-2351.

32. Foo E, Bullier E, Goussot M, Foucher F, Rameau C, Beveridge CA: The branching gene RAMOSUS1 mediates interactions among two novel signals and auxin in Pea. Plant Cell 2005, 17:464-474.

33. Millar AA, Clemens S, Zachgo S, Giblin EM, Taylor DC, Kunst L: CUT1, an arabidopsis gene required for cuticular wax biosynthesis and pollen fertility, encodes a very-long-chain fatty acid condensing enzyme. Plant Cell 1999, 11:825-838.

34. Ji XM, Raveendran M, Oane R, Ismail A, Lafitte R, Bruskiewich R, Cheng SH, Bennett J: Tissue-specific expression and drought responsiveness of cellwall invertase genes of rice at flowering. Plant Mol Biol 2005, 59:945-64.

35. Kader JC: Lipid-transfer protein in plants. Ann Rev Plant Physiol Plant Mol Biol 1996, 47:627-654.

36. Bray EA: Genes commonly regulated by water-deficit stress in Arabidopsis thaliana. Journal of Experimental Botany 2004, 55:2331-2341.

37. Minic Z, Jouanin L: Plant glycoside hydrolases involved in cell wall polysaccharide degradation. Plant Physiology and Biochemistry 2006, 44:435-449.

38. Horvath DP, Chao WS, Anderson JV: Molecular analysis of signals controlling dormancy and growth in underground adventitious buds of leafy spurge. Plant Physiology 2002, 128:1439-1446.

39. Jukanti AK, Nancy Heidlebaugh M, Parrott DL, Isabelle Fischer A, McInnerney K, Fischer AM: Comparative transcriptome profiling of nearisogenic barley (Hordeum vulgare) lines differing in the allelic state of a major grain protein content locus identifies genes with possible roles in leaf senescence and nitrogen reallocation. New Phytologist 2008, 177:333-349.

40. Sakamoto T, Kobayashi M, Itoh $H$, Tagiri A, Kayano T, Tanaka H, Iwahori S, Matsuoka M: Expression of a gibberellin 2-oxidase gene around the shoot apex is related to phase transition in rice. Plant Physiology 2001, 125:1508-1516.

41. Lawton KA, Beck J, Potter S, Ward E, Ryals J: Regulation of cucumber classIII chitinase gene expression. Molecular Plant-Microbe Interactions 1994, 7:48-57.

42. Teixeira J, Pereira S: High salinity and drought act on an organdependent manner on potato glutamine synthetase expression and accumulation. Environmental and Experimental Botany 2007, 60(1):121-126.

43. Teixeira J, Fidalgo F: Salt stress affects glutamine synthetase activity and mRNA accumulation on potato plants in an organ-dependent manner. Plant Physiol Biochem 2009, 47(9):807-813.

44. Gao G, Zhong Y, Guo A, Zhu Q, Tang W, Zheng W, Gu X, Wei L, Luo J: DRTF: a database of rice transcription factors. Bioinformatics 2006, 22:1286-1287.
45. Nijhawan A, Jain M, Tyagi AK, Khurana JP: Genomic survey and gene expression analysis of the basic leucine zipper transcription factor family in rice. Plant Physiology 2008, 146(2):333-350.

46. Zhang ZJ, Wang D, Fu BY: Expression patterns of rice bHLH genes responsive to environmental stresses. Molecular Plant Breeding 2008, 6(3):425-431.

47. Nuruzzaman M, Manimekalai R, Sharoni AM, Satoh K, Kondoh H, Ooka H, Kikuchi : Genome-wide analysis of NAC transcription factor family in rice. Gene 2010, 465(1-2):30-44.

48. Dai X, Xu Y, Ma Q, Xu W, Wang T, Xue Y, Chong K: Overexpression of an R1R2R3 MYB gene, OSMYB3R-2, increases tolerance to freezing, drought, and salt stress in transgenic Arabidopsis. Plant Physiol 2007, 143(4):1739-51.

49. Fang Y, You J, Xie K, Xie W, Xiong L: Systematic sequence analysis and identification of tissue-specific or stress-responsive genes of NAC transcription factor family in rice. Mol Genet Genomics 2008, 280(6):547-63.

50. Kizis $D$, Lumbreras $V$, Pagè $M$ : Role of AP2/EREBP transcription factors in gene regulation during abiotic stress. FEBS Letters 2001, 498:187-189.

51. Shinozaki K, Yamaguchi-Shinozaki K: Gene networks involved in drought stress response and tolerance. J Exp Bot 2007, 58:221-227.

52. Jin $P$, Huang $L Y$, Wang $D$, Wu HM, Zhu LH, Fu BY: Expression profiling of rice AP2/EREBP genes responsive to abiotic stresses. Scientia Agricultura Sinica 2009, 42(11):3765-3773.

53. Drews GN, Bowman JL, Meyerowitz EM: Negative regulation of the Arabidopsis homeotic gene AGAMOUS by the APETALA2 product. Cell 1991, 65:991-1002.

54. Krizek BA: AINTEGUMENTA and AINTEGUMENTALIKE6 6 act redundantly to regulate Arabidopsis floral growth and patterning. Plant Physiol 2009, 150:1916-1929.

55. Karim MR, Hirota A, Kwiatkowska D, Tasaka M, Aida M: A role for Arabidopsis PUCHI in floral meristem identity and bract suppression. Plant Cell 2009, 21:1360-1372.

56. Yang T, Poovaiah BW: A calmodulin-binding/CGCG box DNA-binding protein family involved in multiple signaling pathways in plants. $J$ Biol Chem 2002, 277:45049-58.

57. Cuming AC, Cho SH, Kamisugi Y, Graham H, Quatrano RS: Microarray analysis of transcriptional responses to abscisic acid and osmotic, salt, and drought stress in the moss Physcomitrella patens. New Phytologist 2007, 176:275-287.

58. Cooper B, Clarke JD, Budworth P, Kreps J, Hutchison D, Park S, Guimil S, Dunn M, Luginbuhl P, Ellero C, Goff SA, Glazebrook J: A network of rice genes associated with stress response and seed development. Proc Natl Acad Sci USA 2003, 100:4945-4950.

59. Chen W, Provart NJ, Glazebrook J, Katagiri F, Chang HS, Eulgem T, Mauch F, Luan S, Zou G, Whitham SA, Budworth PR, Tao Y, Xie Z, Chen X, Lam S, Kreps JA, Harper JF, Si-Ammour A, Mauch-Mani B, Heinlein M, Kobayashi K, Hohn T, Dangl JL, Wang X, Zhu T: Expression profile matrix of Arabidopsis transcription factor genes suggests their putative functions in response to environmental stresses. Plant Cell 2002, 14:559-574.

doi:10.1186/1471-2164-12-149

Cite this article as: Wang et al: Genome-wide temporal-spatial gene expression profiling of drought responsiveness in rice. BMC Genomics 2011 12:149.

\section{Submit your next manuscript to BioMed Central and take full advantage of:}

- Convenient online submission

- Thorough peer review

- No space constraints or color figure charges

- Immediate publication on acceptance

- Inclusion in PubMed, CAS, Scopus and Google Scholar

- Research which is freely available for redistribution

Submit your manuscript at www.biomedcentral.com/submit
C Biomed Central 